\title{
Circulating dipeptidyl peptidase 3 on intensive care unit admission is a predictor of organ dysfunction and mortality
}

\author{
Attila Frigyesi ${ }^{1,2^{*}} \mathbb{D}$, Maria Lengquist ${ }^{1,2}$, Martin Spångfors ${ }^{1,3}$, Martin Annborn ${ }^{1,4}$, Tobias Cronberg ${ }^{1,5}$, \\ Niklas Nielsen ${ }^{1,4}$, Helena Levin ${ }^{1,6}$ and Hans Friberg ${ }^{1,2}$
}

\begin{abstract}
Background: Our aim was to investigate the prognostic potential of circulating dipeptidyl peptidase 3 (cDPP3) to predict mortality and development of organ dysfunction in a mixed intensive care unit (ICU) population, and for this reason, we analysed prospectively collected admission blood samples from adult ICU patients at four Swedish hospitals. Blood samples were stored in a biobank for later batch analysis. The association of cDPP3 levels with 30-day mortality and Sequential Organ Failure Assessment (SOFA) scores on day two was investigated before and after adjustment for the simplified acute physiology score III (SAPS-3), using multivariable (ordinal) logistic regression. The predictive power of CDPP3 was assessed using the area under the receiver operating characteristic curve (AUROC).

Results: Of 1978 included consecutive patients in 1 year (2016), 632 fulfilled the sepsis 3-criteria, 190 were admitted after cardiac arrest, and 157 because of trauma. Admission CDPP3 was independently (of SAPS-3) associated with 30-day mortality with odds ratios of 1.45 (95\% confidence interval (CI) 1.28-1.64) in the entire ICU population, 1.30 $(95 \% \mathrm{Cl} 1.08-1.57)$ in the sepsis subgroup and 2.28 (95\% Cl 1.50-3.62) in cardiac arrest. For trauma, there was no clear association. Circulating DPP3 alone was a moderate predictor of 30-day mortality with AUROCs of $0.68,0.62$, and 0.72 in the entire group, the sepsis subgroup, and the cardiac arrest subgroup, respectively. By adding CDPP3 to SAPS-3, AUROC improved for the entire group, the sepsis subgroup, and the cardiac arrest subgroup ( $p=0.023)$.
\end{abstract}

Conclusion: Circulating DPP3 on admission is a SAPS-3 independent prognostic factor of day-two organ dysfunction and 30-day mortality in a mixed ICU population and needs further evaluation.

Keywords: Circulating dipeptidyl peptidase 3, Biomarker, Intensive care, Sepsis, Cardiac arrest, Trauma, Mortality, Organ dysfunction

\section{Introduction}

A variety of patients with different severity of critical illness are treated in intensive care units (ICUs). The severity of illness on ICU admission is commonly assessed using the Simplified Acute Physiology Score III (SAPS-3), which includes laboratory and physiological measures and

*Correspondence: attila.frigyesi@med.lu.se

'Department of Clinical Medicine, Anaesthesiology and Intensive Care, Lund University, SE-22185 Lund, Sweden

² kåne University Hospital, Intensive and Perioperative Care, SE-22185 Lund, Sweden

Full list of author information is available at the end of the article comorbidities. There is a need for novel prognostic and discriminatory biomarkers that could improve and simplify the complex SAPS-3 model or replace a standalone biomarker as lactate.

Circulating dipeptidyl peptidase 3 (cDPP3), also known as red cell angiotensinase, is an enzyme with a molecular mass of $83 \mathrm{kDa}[1]$. The cDPP3 gene is ubiquitously expressed, but its exact function is not understood. Recent findings indicate a role not only in protein metabolism but also in blood pressure regulation, pain modulation, 
and inflammatory processes based on the substrate specificity of cDPP3 [2]. The main features of the peptidase come from its ability to cleave different substances, e.g. enkephalins, endorphins, and specifically, angiotensin II [3-5], but the role of extracellular cDPP3 in pathology and disease is largely unknown [6-8].

Our aim was to investigate the prognostic role of cDPP3 levels on ICU admission in relation to 30-day mortality and the day-two SAPS-3 score. Furthermore, we wanted to examine the role of cDPP3 in three well-characterised and defined subgroups in the ICU: sepsis, cardiac arrest, and trauma. Our primary outcome was 30-day mortality, and the secondary outcome was organ dysfunction on day two.

\section{Materials and methods Study design and setting}

This study is a multicentre observational study where blood samples were prospectively collected and retrospectively analysed. The Standards for Reporting of Diagnostic Accuracy Studies (STARD) guidelines were followed [9].

\section{Participants}

All patients admitted to any of four mixed surgical and medical ICUs in southern Sweden in 1 year (2016) were evaluated for eligibility. Adult patients with valid blood samples were included. The sepsis subgroup was identified using the sepsis-3 criteria, a detailed description of which has been presented in a previous article [10]. The cardiac arrest subgroup was identified using the International Statistical Classification of Diseases and Related Health Problems (ICD) code I46.9 at ICU discharge. The trauma subgroup was identified through multi-trauma as the reason for ICU admission. When transfers occurred between the participating ICUs, follow-up data were merged to form cohesive ICU admissions.

\section{Variables}

The third version of the Simplified Acute Physiology Score (SAPS-3) was calculated [11, 12] based on physiological parameters and laboratory findings recorded within $1 \mathrm{~h}$ before/after ICU admission.

The Sequential Organ Failure Assessment (SOFA) score was recorded daily during the ICU stay [13]. The day-two SOFA was the first score to be based on a full 24-h period following admission and therefore used. The total SOFA score was based on the available SOFA subscores.

\section{Data sources}

Background and survival data were extracted from the Patient Administrative System for Intensive Care Units (PASIVA). PASIVA is the portal by which the treating physician and nursing staff submit prospectively collected laboratory and physiological data to the Swedish Intensive
Care Registry (SIR). PASIVA is synchronised with the Swedish population register, which contains survival data.

The blood samples were collected in EDTA (ethylenediaminetetraacetic acid) vacutainers at ICU admission, centrifuged, aliquoted, frozen, and stored in the SWECRIT biobank at Region Skåne (registration no. BD-47). For inclusion, the sample had to be collected within $6 \mathrm{~h}$ after ICU admission. If the sampling time was missing, samples were included if the time of freezing was within the 6-h time frame. Frozen plasma samples were shipped and batch analysed in a blinded fashion on thawed samples in 2019 at the laboratory of SphingoTec GmbH (Hennigsdorf, Germany).

A median of $14.5 \mathrm{ng} / \mathrm{mL}$ and a 97.5 percentile of 40.0 $\mathrm{ng} / \mathrm{mL}$ was previously identified in a group of healthy volunteers aged $56-87$ years $^{1}$ (personal communication SphingoTec $\mathrm{GmbH}$ ).

\section{Bias}

Potential selection bias was investigated in a comparison of baseline characteristics between included and excluded patients.

\section{Study population size}

The study used a convenience sample, and the study size was based on the number of ICU admissions and corresponding valid blood samples during the study period.

\section{Quantitative variables}

The distribution of cDPP3 levels was highly skewed, and therefore all analyses were carried out on a logarithmic scale (base 10).

\section{Statistical methods}

The association between cDPP3 levels and 30-day mortality was analysed using multivariable logistic regression, also including the SAPS-3 score as an independent variable. Circulating DPP3 was included as a z-normalised (subtracted mean and then divided by one standard deviation) base-10 log-transformed independent variable. The regression models were evaluated with the HosmerLemeshow goodness-of-fit test with ten groups, and only models resulting in non-significant tests were reported [14]. The association between cDPP3 levels and day-two SOFA scores were analysed using multivariable ordinal logistic regression [15].

To evaluate the additional value of CDPP3 to SAPS-3 in the logistic regression model, we calculated the area under the receiver operating characteristic curve (AUROC) [16]. Differences in AUROCs were tested with the method of DeLong et al. [17].

Modified correlation networks for cDPP3 and day-two SOFA scores were visualised using the corrr ${ }^{2}$ package

${ }^{1}$ https://www.malmo-kohorter.lu.se/mpp

${ }^{2}$ https://corrr.tidymodels.org 
in $\mathrm{R}$. The product of the Kendall $\tau$ and the $1-p$ were visualised so that highly correlated points (SOFA subscores or cDPP3) with low $p$-values were close and had strong vertices. The strength of the connections was indicated by the colour intensity of the vertices. The proximity of points was based on multidimensional clustering.

\section{Ethics and consent}

Ethical approval was obtained from the Regional Ethical Review Board of Lund, Sweden (registration nos. 2015/267 and 2017/802). Patients and their next-of-kin were given the possibility to opt out.

\section{Results}

\section{Participants}

Out of 2546 adult ICU admissions, 1978 (78\%) had valid blood samples at ICU admission and did not opt out. Of the 1978 admissions, the sepsis subgroup constituted 32\% $(\mathrm{n}=632)$, the cardiac arrest subgroup 9.6\% $(\mathrm{n}=190)$ and the trauma subgroup $7.9 \%(\mathrm{n}=157)$. There was no overlap between the sepsis and the cardiac arrest subgroups (cardiac arrest was an exclusion criterion for sepsis). Of the trauma group $6.5 \%$ were identified as having sepsis 3 on admission, and $1.3 \%$ of the trauma patients also had a cardiac arrest. See Supplementary $1 \mathrm{~F} 1$ for a flow chart.

The median time from ICU admission to blood sampling for cDPP3 was $21 \mathrm{~min}$ (interquartile range (IQR) 15-40 $\mathrm{min}$ ). The mean time from ICU admission to the start of day-two SOFA was $17.5 \mathrm{~h}$ (standard deviation 6.2 h).

\section{Descriptive data}

The median (IQR) cDPP3 concentration was 19 (13-33) $\mathrm{ng} / \mathrm{mL}$ for the entire ICU population, 19 (13-31) $\mathrm{ng} / \mathrm{mL}$ for the sepsis group, 44 (29-69) $\mathrm{ng} / \mathrm{ml}$ in the cardiac arrest group and 22 (14-38) in the trauma group, see Table 1. See Fig. 1 for the distribution of cDPP3.

The female to male ratio, ICU length-of-stay (LOS), ICU mortality, 30-day mortality, morbidity as measured by SAPS-3, median age, and factors included in the SAPS-3 score are presented in Table 1.

The patients excluded from the study were slightly younger, had lower mortality, and a shorter ICU length-ofstay (Supplementary $1 \mathrm{~T} 1$ ). The excluded group included fewer sepsis patients but more trauma patients. The fraction of missing parameters was mostly low (Supplementary 1 T2).

\section{Unadjusted outcomes}

The association between cDPP3 levels and mortality is shown in Fig. 1. The unadjusted associations between cDPP3 levels and 30-day mortality and day-two SOFA scores, respectively, from (ordinal) logistic regressions, are reported as odds ratios (ORs) in Table 2. The logistic regression models resulted in an AUROC of 0.68 (95\% CI $0.65-0.71$ ) for the entire population, 0.62 (95\% CI $0.57-$ $0.67)$ for the sepsis group, $0.72(95 \%$ CI $0.65-0.80)$ for the cardiac arrest group, and 0.53 (95\% CI $0.40-0.67$ ) for the trauma group .

\section{SAPS-3 adjusted mortality}

The multivariable logistic 30-day mortality regression ORs for cDPP3 after correction for SAPS-3 were 1.45 (95\% CI 1.28-1.64, $p<0.001$ ) in the entire ICU population, 1.30 (95\% CI 1.08-1.57, $p=0.0050$ ) in the sepsis subgroup, 2.28 (95\% CI 1.50-3.62, $p<0.001$ ) for the cardiac arrest subgroup, and 1.11 (95\% CI 0.58-2.10, $p=0.74$ ) in the trauma subgroup.

In the entire population, the logistic regression models using SAPS-3 alone resulted in an AUROC of 0.81 (95\% CI $0.79-0.83$ ) versus 0.82 (95\% CI 0.80-0.84) when CDPP3 was added $(\mathrm{p}=0.0049)$. For the sepsis population, the AUROC was 0.73 (95\% CI 0.69-0.77) using SAPS-3 alone versus 0.74 (95\% CI $0.70-0.78)$ adding $\mathrm{CDPP} 3(\mathrm{p}=0.023)$. For the cardiac arrest population, the AUROC was 0.74 (95\% CI 0.67-0.82) using SAPS-3 alone versus 0.80 (95\% CI 0.73-0.86) when cDPP3 was added ( $\mathrm{p}=0.0091)$. For the trauma population, the AUROC was 0.84 (95\% CI $0.77-$ 0.92) using SAPS-3 alone versus 0.84 (95\% CI 0.77-0.92) when $\mathrm{cDPP} 3$ was added $(\mathrm{p}=0.59)$.

\section{Correlation analyses}

Modified correlation networks (to visualise the strength of correlation) between cDPP3 and day-two SOFA scores are visualised (as described in the Statistics section) in Fig. 2. It was evident that the day-two hepatic SOFA scores were (significantly) correlated with the daytwo coagulation SOFA scores. In the whole population, cDPP3 was positively correlated with the neurological SOFA score (CNS), the hepatic/coagulation group, and the renal/cardiovascular group. In sepsis, cDPP3 was positively (and significantly) correlated with the hepatic/coagulation group. In cardiac arrest, the positive correlation (and significance) for cDPP3 was strongest for neurological SOFA.

\section{Discussion}

In the present study, we investigated the prognostic capability of CDPP3 in a large, general ICU population and its association with mortality and organ dysfunction. Our ICU population had three well-defined subgroups: sepsis, cardiac arrest, and trauma, which comprised half of the study population. The remaining patients were a mix of medical, surgical, and postoperative patients, normally cared for in a general, mixed ICU.

We found that the cDPP3 level on admission was a SAPS-3 independent prognostic factor for 30-day mortality. The added (to SAPS-3) prognostic capability of cDPP3 
Table 1 Descriptive statistics for the whole ICU population, the sepsis-3 subgroup, the cardiac arrest subgroup and the trauma subgroup. If not stated otherwise, values represent medians (interquartile ranges, IQR)

\begin{tabular}{|c|c|c|c|c|}
\hline & ICU & Sepsis & Cardiac arrest & Trauma \\
\hline Number of patients & 1978 & $632(32 \%)$ & $190(9.6 \%)$ & $157(7.9 \%)$ \\
\hline Women (\%) & 39 & 40 & 27 & 23 \\
\hline ICU length-of-stay (days) & $1.7(0.8-3.8)$ & $2.5(1.1-5.5)$ & $2.4(0.97-4.3)$ & $1.8(0.93-4.1)$ \\
\hline ICU mortality (\%) & 11 & 14 & 34 & 4.5 \\
\hline 30-day mortality (\%) & 22 & 28 & 54 & 12 \\
\hline SAPS-3 score & $59(47-71)$ & $66(57-77)$ & $76(66-87)$ & $48(39-59)$ \\
\hline Day-one SOFA score & $7(4-10)$ & $8(6-11)$ & $10(8-13)$ & $5(2-7)$ \\
\hline Day-two SOFA score $(n=995)$ & $8(5-10)$ & $8(6-11)$ & $10(8-12)$ & $6(4-9)$ \\
\hline CRRT during ICU stay (\%) & 9.2 & 15 & 7.4 & 0.6 \\
\hline \multicolumn{5}{|l|}{ Box I } \\
\hline Age (years) & $66(54-74)$ & $69(61-76)$ & $68(60-76)$ & $55(33-70)$ \\
\hline \multicolumn{5}{|l|}{ Comorbidities } \\
\hline - Cancer therapy (\%) & 4.6 & 6.3 & 4.2 & 0.6 \\
\hline - Chronic heart failure (\%) & 5.5 & 7.0 & 10 & 1.3 \\
\hline - Haematological cancer (\%) & 2.6 & 5.2 & 1.0 & 0 \\
\hline - Liver cirrhosis (\%) & 1.1 & 1.6 & 0 & 0 \\
\hline - Cancer (\%) & 10.4 & 10.4 & 7.9 & 1.3 \\
\hline Vasoactive drugs before ICU (\%) & 44 & 47 & 64 & 21 \\
\hline \multicolumn{5}{|l|}{ Box II } \\
\hline \multicolumn{5}{|l|}{ Surgical status at ICU admission } \\
\hline - No surgery (\%) & 74 & 85 & 94 & 83 \\
\hline \multicolumn{5}{|l|}{ Box III } \\
\hline GCS & $13(10-15)$ & $13(10-15)$ & $3(3-8)$ & $10(6-15)$ \\
\hline Total bilirubin ( $\mu \mathrm{mol} / \mathrm{L})$ & $9(6-15)$ & $10(7-19)$ & $8(5-12)$ & $8(5-12)$ \\
\hline Max. temperature $\left({ }^{\circ} \mathrm{C}\right)$ & $37.0(36.3-37.6)$ & $37.3(36.5-38.1)$ & $36.0(35.5-36.8)$ & $37.0(36.0-37.5)$ \\
\hline Max. creatinine ( $\mu \mathrm{mol} / \mathrm{L})$ & $93(70-145)$ & $119(79-205)$ & $112(87-149)$ & $87(74-111)$ \\
\hline Max. heart rate (bpm) & $100(80-118)$ & $107(90-122)$ & $98(80-115)$ & $90(80-110)$ \\
\hline Max. leukocyte count $\left(\times 10^{9} / \mathrm{L}\right)$ & $13(8.8-18)$ & $13(8.4-19)$ & $16(12-21)$ & $14(11-19)$ \\
\hline Min. pH & $7.34(7.24-7.41)$ & $7.32(7.20-7.40)$ & $7.19(7.04-7.3)$ & $7.34(7.29-7.40)$ \\
\hline Min. platelet count $\left(\times 10^{9} / \mathrm{L}\right)$ & $221(161-286)$ & $218(147-304)$ & $222(165-270)$ & $212(171-261)$ \\
\hline Min. systolic blood pressure (mmHg) & $100(80-120)$ & $91(75-115)$ & $85(68-109)$ & $104(90-130)$ \\
\hline \multicolumn{5}{|l|}{ Oxygenation } \\
\hline - Respiratory support (\%) & 58 & 59 & 86 & 53 \\
\hline$-\mathrm{FiO}_{2}(\%)$ & $50(40-70)$ & $60(40-80)$ & $60(50-80)$ & $45(40-57)$ \\
\hline$-\mathrm{PaO}_{2}(\mathrm{kPa})$ & $13(9.8-18)$ & $11(9.0-15)$ & $13(11-22)$ & $16(11-24)$ \\
\hline \multicolumn{5}{|l|}{ Other } \\
\hline cDPP3 (ng/mL) & $19(13-33)$ & $19(13-31)$ & $44(28-69)$ & $22(14-38)$ \\
\hline
\end{tabular}

Box I-III refers to the subsections of the SAPS-3 scoring system. ICU intensive care unit, SAPS-3 simplified acute physiology score III, SOFA Sequential Organ Failure Assessment, CRRT continuous renal replacement therapy, GCS Glasgow coma scale, $\mathrm{FiO}_{2}$ fraction of inspired oxygen, $\mathrm{PaO}_{2}$ arterial partial pressure of oxygen, $\mathrm{CDPP} 3$ circulating dipeptidyl peptidase 3

to predict mortality was assessed using AUROC and was most pronounced in the cardiac arrest subgroup. We also found that the cDPP3 level on admission was associated with all types of day-two organ dysfunction as defined by SOFA.
Circulating DPP3 cleaves angiotensin II and can thus be surmised to have a role in cardiovascular compromise as Dépret demonstrated in burns patients [18]. Deniau et al. investigated the association of cDPP3 levels and mortality in cardiogenic shock patients and 


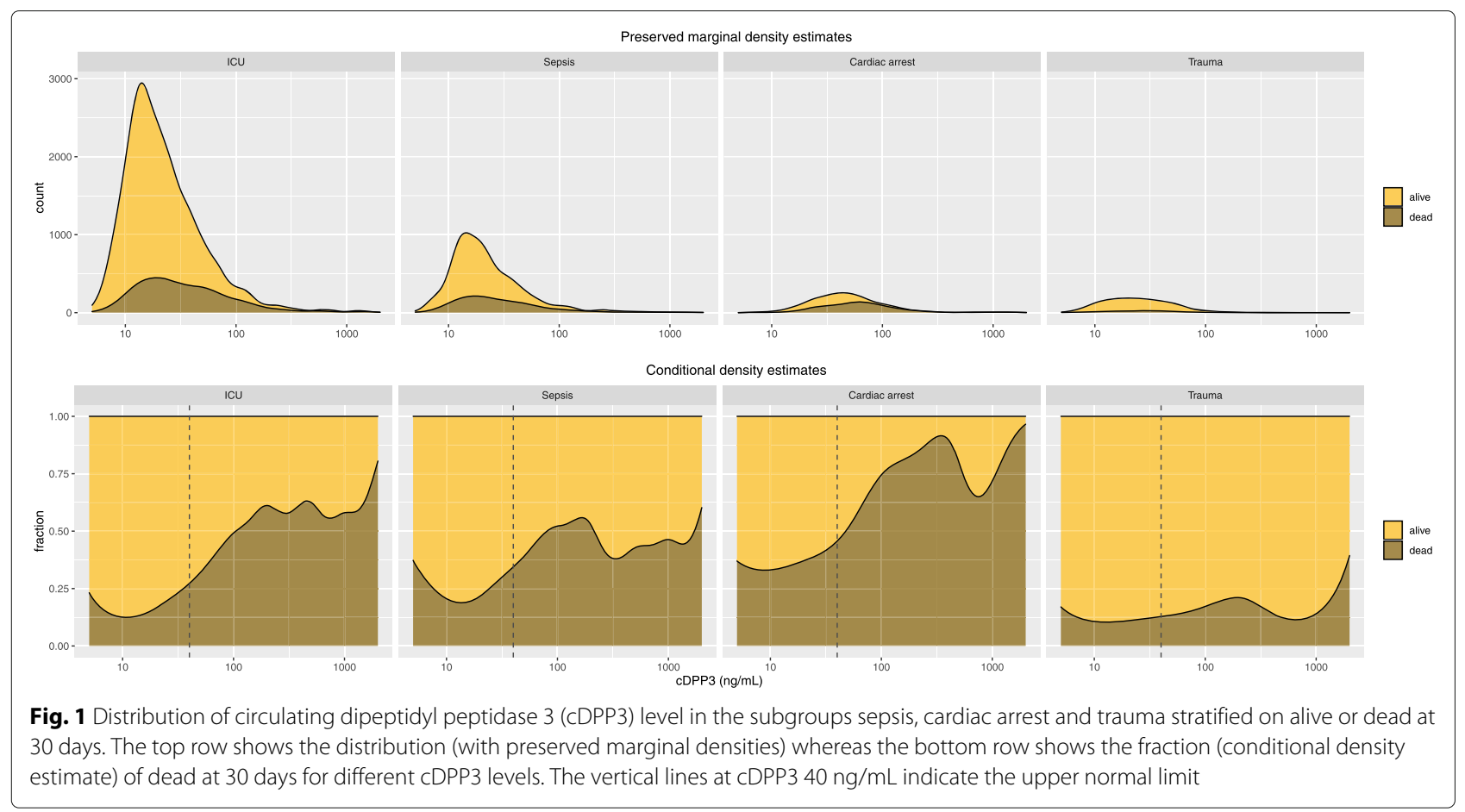

the association between high cDPP3 and organ function in a heart failure model in mice [7]. They demonstrated that cDPP3 is a myocardial depressant factor associated with mortality in severe heart failure patients. Furthermore, inhibition of cDPP3 by Procizumab, a specific cDPP3 antibody, improved hemodynamics in a mouse model of heart failure. Takagi et al. showed that CDPP3 values were higher in refractory cardiogenic shock after acute myocardial infarction [8].

Circulating DPP3 is not cleared by the kidneys. Angiotensin II is not the only substrate for DPP3; there are also metenkephalin and leucine enkephalin. Enkephalins are endogenous opioids that are widely expressed and act primarily on $\delta$-opioid receptors, which are primarily expressed in the central nervous system and the kidney. It has been suggested that enkephalins have a regulatory role in kidney function, such as inducing diuresis and natriuresis [19]. Although elevated CDPP3 was associated with all types of organ dysfunction, the correlation network analysis (Fig. 2) revealed that elevated cDPP3 was mainly associated with day-two renal, neurologic, hepatic and coagulation dysfunction.

Rehfeld and colleagues found cDPP3 to be elevated in

Table 2 Odds ratios (ORs) for dipeptidyl peptidase 3 (DPP3) from univariate (ordinal) logistic regressions on 30-day mortality and day-two SOFA scores

\begin{tabular}{|c|c|c|c|c|c|c|c|c|c|c|c|c|}
\hline \multirow{2}{*}{$\begin{array}{l}\text { Univariate } \\
\text { Outcome }\end{array}$} & \multicolumn{3}{|l|}{ ICU } & \multicolumn{3}{|c|}{ Sepsis } & \multicolumn{3}{|c|}{ Cardiac arrest } & \multicolumn{3}{|c|}{ Trauma } \\
\hline & OR & $95 \% \mathrm{Cl}$ & $p$-value & OR & $95 \% \mathrm{Cl}$ & $p$-value & OR & $95 \% \mathrm{Cl}$ & $p$-value & OR & $95 \% \mathrm{Cl}$ & $p$-value \\
\hline Mortality & 1.88 & $1.69-2.10$ & $<0.001$ & 1.49 & $1.26-1.78$ & $<0.001$ & 2.57 & $1.74-3.97$ & $<0.001$ & 1.12 & $0.63-1.94$ & 0.69 \\
\hline $\begin{array}{l}\text { Cardiovasc. } \\
\text { SOFA }\end{array}$ & 1.28 & $1.14-1.43$ & $<0.001$ & 1.03 & $0.86-1.24$ & 0.75 & 1.69 & $1.09-2.72$ & 0.025 & 1.24 & $0.82-1.89$ & 0.31 \\
\hline Resp. SOFA & 1.29 & $1.15-1.45$ & $<0.001$ & 1.18 & $0.98-1.44$ & 0.088 & 1.10 & $0.72-1.71$ & 0.65 & 1.03 & $0.68-1.56$ & 0.88 \\
\hline Renal SOFA & 1.52 & $1.35-1.72$ & $<0.001$ & 1.45 & $1.20-1.76$ & $<0.001$ & 1.72 & $1.11-2.67$ & 0.014 & 1.33 & $0.81-2.21$ & 0.25 \\
\hline $\begin{array}{l}\text { Hepatic } \\
\text { SOFA }\end{array}$ & 1.69 & $1.46-1.95$ & $<0.001$ & 1.85 & $1.48-2.32$ & $<0.001$ & 1.84 & $0.98-3.45$ & 0.054 & 1.89 & $1.01-3.70$ & 0.052 \\
\hline Neurol. SOFA & 1.62 & $1.44-1.82$ & $<0.001$ & 1.32 & $1.10-1.59$ & 0.0032 & 3.28 & $1.81-6.29$ & 0.035 & 1.36 & $0.85-2.18$ & 0.20 \\
\hline Coag. SOFA & 1.46 & $1.29-1.65$ & $<0.001$ & 1.57 & $1.28-1.94$ & $<0.0012$ & 1.73 & $1.11-2.72$ & 0.016 & 1.57 & $1.01-2.51$ & 0.050 \\
\hline
\end{tabular}

Cl confidence interval, SOFA Sequential Organ Failure Assessment 


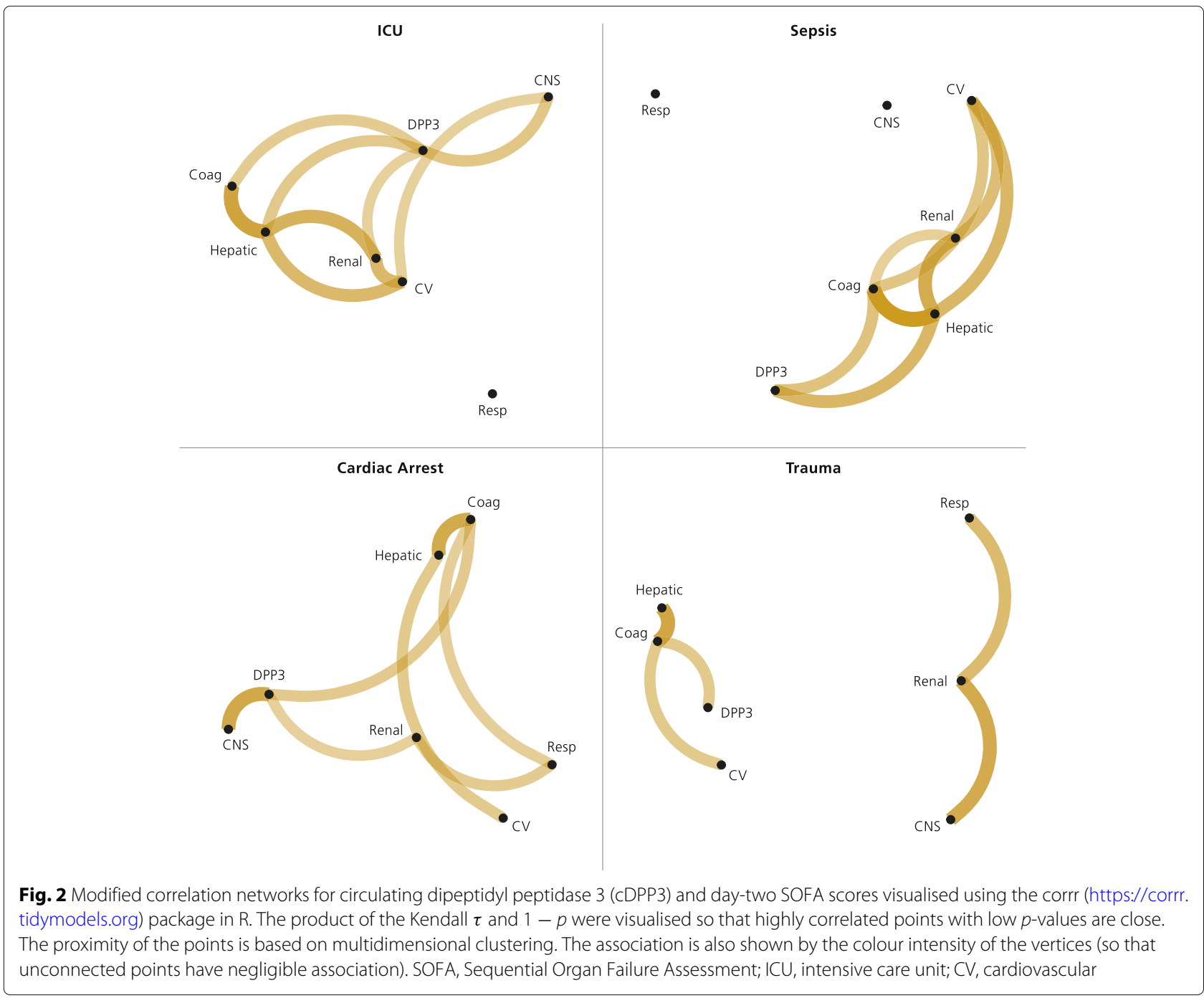

sepsis patients and that higher levels were associated with the severity of disease [6]. We have shown here that cDPP3 was a prognostic factor for organ dysfunction on day two and a SAPS-3 independent predictor of 30-day mortality in sepsis. The correlation network analysis revealed that in sepsis, cDPP3 was primarily associated with hepatic and coagulation dysfunction and, to a somewhat lesser degree, renal dysfunction and neurological dysfunction.

In trauma, we could not show that cDPP3 improved mortality prediction as compared to SAPS-3 (possibly due to lacking power). Elevated cDPP3 was only associated with coagulation dysfunction (and borderline significant with hepatic dysfunction), which was confirmed by the correlation network analysis.

The strong association with day-two neurological SOFA in the cardiac arrest subgroup, which was also confirmed in the correlation network analysis, is suggestive of cDPP3 being a marker of brain injury. It is also worth noting how sharply mortality increases as cDPP3 exceeds the upper normal level of $40 \mathrm{ng} / \mathrm{mL}$. Compared to the entire ICU population, the cardiac arrest subgroup was more severely ill on admission, reflected in higher SAPS-3 and SOFA scores. For cardiac arrest patients, the day-two neurological SOFA is typically determined by the level of consciousness on admission since a vast majority of cardiac arrest patients will still be sedated as part of a target temperature management (TTM) strategy [20].

Since we did not measure DPP3 in the cerebrospinal fluid in this study, we refrain from making direct assumptions about DPP3 activity on central nervous system activity. In this study, we report an association between high DPP3 blood levels at admission and increased neurological SOFA score, an association that deserves further exploration, including serial samples during ICU care. Measurement of DPP3 activity in the cerebrospinal fluid would also be of great interest. Enkephalin, an 
important signalling molecule in the brain, is a wellknown DPP3 substrate, and the correlation between DPP3 concentrations in the bloodstream and the central nervous system should be investigated in future studies.

To summarise the association of cDPP3 and organ dysfunction, our findings suggest that there may be a hepaticcoagulation dysfunction component in CDPP3 elevation in the entire population and in the subgroups sepsis, cardiac arrest and trauma as well as there may be a brain injury component primarily in cardiac arrest.

A strength of our study is the well-defined subgroups. The sepsis subgroup was carefully characterised and described in a previous study [10]. The cardiac arrest and trauma subgroups are common diagnoses in the ICU and generally easily identified. Another strength is that we adjusted for age, comorbidities, and acute severity of illness through the validated SAPS-3 score. After adjustments, our results are still robust, showing that cDPP3 provides clinically important additional prognostic information in a general ICU population, not captured by SAPS-3.

\section{Limitations}

A weakness of our study is that we are confined to admission samples. Another weakness is that only half of the ICU population was characterised into broad diagnostic subgroups.

It is, however, important to remember that the predictive value of CDPP3 is dependent on the type of model, and non-logistic interactions with SAPS-3 or any of its constituent variables may not be captured using logistic regression. Machine learning methods, such as neural networks, will likely improve the predictive power of DPP3 but requires even larger data sets [21].

\section{Interpretation}

To our knowledge, this is the first study investigating the importance of cDPP3 levels on ICU admission, opening up a novel possible path of risk assessment of critically ill patients. Additionally, an improved understanding of the role of cDPP3 in the intensive care setting may offer therapeutic possibilities in the future [7].

\section{Generalisability}

The multicentre approach, with ICUs from a large university hospital and regional hospitals, makes the results applicable to ICU populations in regions with similar demographics as Sweden.

\section{Conclusion}

In this study, we found cDPP3 to be a SAPS-3 independent predictor of 30-day mortality and associated with subsequent organ dysfunction in a general ICU population, as well as in sepsis, cardiac arrest, and trauma.

\section{Supplementary Information}

The online version contains supplementary material available at https://doi.org/10.1186/s40560-021-00561-9.

Additional file 1: Supplementary figure 1 and 2, table 1 and 2.

\section{Abbreviations}

CDPP3: circulating dipeptidyl peptidase 3; ICU: intensive care unit; SOFA: Sequential Organ Failure Assessment; SAPS-3: simplified acute physiology score III; EDTA: ethylene diamine tetraacetic acid-plasma; IQR: interquartile range; LOS: length-of-stay; OR: odds ratio

\section{Authors' contributions}

HF and AF designed the study. HL designed the biobank and compiled the data set. AF performed the statistical analyses and prepared the figures. AF wrote the initial manuscript. All authors contributed to the final manuscript.

\section{Funding}

Regional research support, Region Skåne; Government funding of clinical research within the Swedish National Health Services (ALF) 2019:YF0053; Biobanking and BioMolecular resources Research Infrastructure (BBMRI, Sweden); Hans-Gabriel and Alice Trolle-Wachtmeister Foundation for Medical Research; European Union Interreg programme IV A; SphingoTec GmbH, Hennigsdorf, Germany, provided all analyses of all samples. The funding organisations had no role in the design and conduct of the study; collection, management, analysis, and interpretation of the data; preparation, review, or approval of the manuscript; or decision to submit the manuscript for publication.

\section{Availability of data and materials}

The data that support the findings of this study are available on request from the corresponding author. The data are not publicly available due to privacy.

\section{Declarations}

\section{Ethics approval and consent to participate}

The study was approved by the Regional Ethical Committee in Lund, Sweden, with reference numbers DNR 2015/267 and DNR 2017/802.

\section{Consent for publication}

Not applicable.

\section{Competing interests}

The authors declare that they have no conflict of interest. Circulating dipeptidyl peptidase 3 was analysed free of charge by SphingoTec $\mathrm{GmbH}$, Neuendorfstraße 15A, 16761 Hennigsdorf, Germany. The authors have no financial or any other interests in SphingoTec GmbH and have not been in any way influenced by the company in writing this research paper.

\section{Author details}

1 Department of Clinical Medicine, Anaesthesiology and Intensive Care, Lund University, SE-22185 Lund, Sweden. ${ }^{2}$ Skåne University Hospital, Intensive and Perioperative Care, SE-22185 Lund, Sweden. ${ }^{3}$ Kristianstad Central Hospital, Anaesthesia and Intensive Care, SE-29185 Kristianstad, Sweden. ${ }^{4}$ Helsingborg Hospital, Anaesthesia and Intensive Care, SE-25187 Helsingborg, Sweden.

${ }^{5}$ Skåne University Hospital, Department of Neurology, SE-22185 Lund, Sweden.

${ }^{6}$ Skåne University Hospital, Research and Education, SE-22185 Lund, Sweden.

Received: 26 April 2021 Accepted: 16 June 2021

Published online: 24 August 2021

References

1. Ellis $S$, Nuenke J. Dipeptidyl arylamidase iii of the pituitary. purification and characterization. J Biol Chem. 1967;242(20):4623-9.

2. Prajapati S, Chauhan S. Dipeptidyl peptidase III: a multifaceted oligopeptide N-end cutter. FEBS J. 2011;278(18):3256-76.

3. Lee C, Snyder S. Dipeptidyl-aminopeptidase iii of rat brain. selective affinity for enkephalin and angiotensin. J Biol Chem. 1982;257(20): 12043-50. 
4. Baršun M, Jajčanin N, Vukelić B, Špoljarić J, Abramić M. Human dipeptidyl peptidase iii acts as a post-proline-cleaving enzyme on endomorphins. Biol Chem. 2007;388(3):343.

5. Kumar P, Reithofer $\mathrm{V}$, Reisinger M, Wallner $\mathrm{S}$, Pavkov-Keller T, Macheroux P, Gruber K. Substrate complexes of human dipeptidyl peptidase III reveal the mechanism of enzyme inhibition. Sci Rep. 2016;6:23787.

6. Rehfeld L, Funk E, Jha S, Macheroux P, Melander O, Bergmann A. Novel Methods for the Quantification of Dipeptidyl Peptidase 3 (DPP3) Concentration and Activity in Human Blood Samples. J Appl Lab Med. 2019;3(6):943-53.

7. Deniau B, Rehfeld L, Santos K, Dienelt A, Azibani F, Sadoune M, Kounde P, Samuel J, Tolpannen H, Lassus J, Harjola V, Vodovar N, Bergmann A, Hartmann O, Mebazaa A, Blet A. Circulating dipeptidyl peptidase 3 is a myocardial depressant factor: dipeptidyl peptidase 3 inhibition rapidly and sustainably improves haemodynamics. Eur J Heart Fail. 2020;22(2): 290-9.

8. Takagi K, Blet A, Levy B, Deniau B, Azibani F, Feliot E, Bergmann A, Santos K, Hartmann O, Gayat E, Mebazaa A, Kimmoun A. Circulating dipeptidyl peptidase 3 and alteration in haemodynamics in cardiogenic shock: results from the OptimaCC trial. Eur J Heart Fail. 2020;22(2):279-86.

9. Bossuyt P, Reitsma J, Bruns D, Gatsonis C, Glasziou P, Irwig L, Lijmer J, Moher D, Rennie D, de Vet H, Kressel H, Rifai N, Golub R, Altman D, Hooft L, Korevaar D, Cohen J, Alonzo T, Altman D, Azuara-Blanco A, Bachmann L, Blume J, Bossuyt P, Boutron I, Bruns D, B? ller H, Buntinx F, Byron S, Chang S, Cohen J, Cooper R, de Groot J, Deeks J, Dendukuri N, Dinnes J, Fleming K, Gatsonis C, Glasziou P, Golub R, Guyatt G, Heneghan C, Hilden J, Hooft L, Horvath R, Hunink M, Hyde C, loannidis J, Janes $H$, Kleijnen J, Knottnerus A, Korevaar A, Kressel H, Lange S, Leeflang M, Lijmer J, Lord S, Lumbreras B, Macaskill P, Magid E, Mallett S, Mclnnes M, McNeil B, McQueen M, Moher D, Moons K, Morris K, Mustafa R, Obuchowski N, Ochodo E, Onderdonk A, Overbeke J, Pai N, Peeling R, Pepe M, Petersen S, Price C, Ravaud P, Reitsma J, Rennie D, Rifai N, Rutjes A, Schunemann H, Simel D, Simera I, Smidt N, Steyerberg E, Straus S, Summerskill W, Takwoingi Y, Thompson M, van de Bruel A, van Maanen H, Vickers A, Virgili G, Walter S, Weber W, Westwood M, Wilczynski N, Ziegler A. STARD 2015: an updated list of essential items for reporting diagnostic accuracy studies. BMJ. 2015;351:5527.

10. Lengquist $M$, Lundberg $O$, Spångfors $M$, Annborn $M$, Levin $H$, Friberg $H$, Frigyesi A. Sepsis is underreported in Swedish intensive care units: A retrospective observational multicentre study. Acta Anaesthesiol Scand. 2020;64(8):1167-76

11. Metnitz P, Moreno R, Almeida E, Jordan B, Bauer P, Campos R, lapichino G, Edbrooke D, Capuzzo M, Le Gall J. Saps 3-from evaluation of the patient to evaluation of the intensive care unit. part 1: Objectives, methods and cohort description. Intensive Care Med. 2005;31(10): 1336-44. https://doi.org/10.1007/s00134-005-2762-6.

12. Moreno $R$, Metnitz $P$, Almeida $E$, Jordan $B$, Bauer $P$, Campos $R$, lapichino G, Edbrooke D, Capuzzo M, Le Gall J. SAPS 3-from evaluation of the patient to evaluation of the intensive care unit. part 2: Development of a prognostic model for hospital mortality at ICU admission. Intensive Care Med. 2005;31(10):1345-55. https://doi.org/10.1007/s00134-005-2763-5.

13. Ferreira F, Bota D, Bross A, Mélot C, Vincent J. Serial evaluation of the SOFA score to predict outcome in critically ill patients. JAMA. 2001;286(14):1754-8.

14. Hosmer D, Lemeshow S, Sturdivant R. Applied Logistic Regression, 3rd. Hoboken: Wiley \& Sons Inc.; 2004, pp. 157-68.

15. Hothorn T, Möst L, Bühlmann P. Most likely transformations. Scand J Stat. 2018;45(1):110-34. https://doi.org/10.1111/sjos.12291.

16. Fawcett T. An introduction to ROC analysis. Pattern Recognit Lett. 27(8): 861-74. https://doi.org/10.1016/j.patrec.2005.10.010..

17. DeLong E, DeLong D, Clarke-Pearson D. Comparing the areas under two or more correlated receiver operating characteristic curves: A nonparametric approach. Biom. 1988;3:837.

18. Dépret F, Amzallag J, Pollina A, Fayolle-Pivot L, Coutrot M, Chaussard M, Santos K, Hartmann O, Jully M, Fratani A, Oueslati H, Cupaciu A, Benyamina M, Guillemet L, Deniau B, Mebazaa A, Gayat E, Farny B, Textoris J, Legrand M. Circulating dipeptidyl peptidase-3 at admission is associated with circulatory failure, acute kidney injury and death in severely ill burn patients. Crit Care. 2020;24(1):168.

19. Khorashadi M, Beunders R, Pickkers P, Legrand M. Proenkephalin: A New Biomarker for Glomerular Filtration Rate and Acute Kidney Injury. Nephron. 2020;144(12):655-61.
20. Nolan J, Soar J, Cariou A, Cronberg T, Moulaert V, Deakin C, Bottiger B, Friberg $\mathrm{H}$, Sunde K, Sandroni C. European Resuscitation Council and European Society of Intensive Care Medicine Guidelines for Post-resuscitation Care 2015: Section 5 of the European Resuscitation Council Guidelines for Resuscitation 2015. Resuscitation. 2015;95:202-22.

21. Holmgren G, Andersson P, Jakobsson A, Frigyesi A. Artificial neural networks improve and simplify intensive care mortality prognostication: a national cohort study of 217,289 first-time intensive care unit admissions. J Intensive Care. 2019;7:44.

\section{Publisher's Note}

Springer Nature remains neutral with regard to jurisdictional claims in published maps and institutional affiliations.
Ready to submit your research? Choose BMC and benefit from:

- fast, convenient online submission

- thorough peer review by experienced researchers in your field

- rapid publication on acceptance

- support for research data, including large and complex data types

- gold Open Access which fosters wider collaboration and increased citations

- maximum visibility for your research: over 100M website views per year

At $\mathrm{BMC}$, research is always in progress.

Learn more biomedcentral.com/submissions 